\title{
CSR and ethics in MSMEs in India
}

\begin{abstract}
The extant literature on CSR and ethics suggests that there is a need for a greater understanding about SMEs. The role of SMEs in the economic growth and development of emerging countries like India is significant. Given the geographical diversity of India and its high reliance on agriculture, MSMEs (medium, small and micro enterprises) are the lifeline of economic development and growth in future. However, the current state of knowledge and practice in the field of CSR and ethics in SMEs in the Indian context is limited. This paper attempts to outline the state of the SME sector in India, Ethics and CSR practices in MSMEs, and identify the knowledge gaps in the field of CSR and ethics in SMEs in India.
\end{abstract}

Key words: India, ethics, CSR, SME, SSI, business ethics

\section{Introduction}

The contribution of the small and medium enterprises (SMEs) to the economic growth of a nation is well recognised. In developing countries, as some authors argue (Leutkenhorst, 2004), the contribution of SMEs towards employment generation is high because they tend to use more labour intensive production processes than large enterprises, boosting employment and leading to more equitable income distribution. In countries, where the disparity levels in income are quite stark and the industrial growth has not been widespread and uniform, the role of the MSMEs in creating employment is quite significant. They also provide livelihood opportunities through simple, value-adding processing activities in agriculture based economies, nurture entrepreneurship and support the building up of systemic productive capacities and the creation of resilient economic systems, through linkages with the large enterprises.

While their significant economic contribution is well understood, their responsible business practices have not been extensively studied for any meaningful interpretation to be drawn. While individually each of these SMEs may not have a significant influence like the large corporations, their cumulative social and environmental impacts could be significant. This is already being witnessed in the textile belts and the chemical belts in India. There is an urgent need therefore

Vasanthi Srinivasan is an Associate Professor in the area of Organisational Behaviour and Human Resource Management at the Indian Institute of Management in Bangalore. She was a Visiting Scholar at the International Centre for Corporate Social Responsibility at the Nottingham University Business School on a British Council Scholarship. The website www. teachcsr.com, an outcome of the scholarship, is intended to promote teaching in Business Ethics and CSR among faculty of business schools in India. to understand the responsible business practices adopted by the SMEs. The importance of CSR among large companies in developing countries is itself of recent origin, no more than a few decades. Therefore, the study of CSR and ethics in SMEs in developing countries assumes greater significance given the rapid economic growth.

Responsible business practices can be conceptualised as consisting of two dimensions - the ethical behaviours of the corporation and the corporate social responsibility (CSR) practices that it adopts. This conceptualisation at an SME level translates to the role of the owners and their ethical orientations and the CSR activities of the enterprises that they own and manage. The CSR and ethics discourse till recently has been dominated by large corporations and CSR in SMEs has received relatively little attention compared to the CSR in large corporations (Moore \& Spence, 2006; Spence \& Rutherford, 2003).

There is a growing consensus that SMEs demonstrate distinctive characteristics, which make them different from large organisations and, therefore, the content, nature and extent of their participation in CSR and ethics is likely to be different (Jenkins, 2006; Tilley, 2000). Some of the characteristics such as smaller size and fewer resources when considered individually (Beekman \& Robinson, 2004), managerial systems where ownership-management separation rarely occurs (Richbell et al., 2006); and, management training that does not always meet the company's real needs (Emiliani, 2000; Park \& Krishnan, 2001) are unique to SME's. In most SMEs, the distinction between the roles of management and ownership is weak, with multitask positions within the organisation being quite common. These enterprises are mainly oriented towards solving day-to-day problems; informal relations and communication predominate here; interpersonal relationships are very important; there is a high degree of interrelation with their environment or communities in which they often act as benefactors or local activists; and finally, they are subject to the market dynamics determined by large enterprises, which in many cases they supply to (Spence, 1999; Spence \& Lozano, 2000; Enderle, 2004). With this heterogeneity, it is expected that the impact on CSR and ethics is likely to be varied. The ethical orientations of owners and their motivation for CSR practices in different contexts has received attention (Vyakarnam et. al, 1997; Spence \& Lozano, 2000; Murillo \& Lozano, 2006) and all these studies also reflect a wide range of perspectives. The need to conclusively demonstrate the differences in CSR in SMEs in differing sizes still exists and since differences 
exist in the adoption of tools and methods across the SMEs (Russo, 2009), it reinforces the need for further research in this area. This paper attempts to understand the state of the field of SMEs in India.

\section{SMEs in India}

The term SME is of relatively recent origin in the Indian context. SMEs were referred to as small scale industry or SSI. The SSI was officially created in the 1950 s. Since 1954, the Government of India has consciously nurtured, promoted and developed SSIs through specific policies as a part of the overall industrial development strategy (Prasad, 2008). Over the last decade, a number of these enterprises needed to compete in global markets as part of supply chains.

The contribution of SMEs to the economic development of India is significant. Their contribution in the total corporate sector is as follows: $40 \%$ of the total volume of production, $80 \%$ of employment, $60 \%$ of the exports and $92 \%$ in terms of enterprises. The SMEs contribute $7 \%$ of India's GDP. As per the Third All India Census of Small Scale Industries conducted in 2004, the SMEs have increased from about 80,000 units in the 1940s to about 10.52 million units. In the sports goods and garments sector their contribution to exports is as high as $90 \%$ to $100 \%$. They constitute $90 \%$ of the industrial units in the country and also contribute to about 35\% of India's exports. (Pandey, 2007) In recent years, beyond the economic growth, there is a greater urgency for 'inclusive growth' in which SMEs are expected to play a critical role. The geographical and socio-cultural diversity of India with 28 states and 16 national languages, coupled with significant disparities in income, and co-existence of poverty and high affluence make the SME sector more critical for India. Out of the 10.52 million units, 55\% are located in rural India (Third All India Census of SSI, 2002). Registration of SMEs has not been compulsory in the Indian context. The sector employs about 25 million persons. About $10 \%$ of this sector consists of womenowned enterprises. About $47 \%$ of the total SMEs were located in five states, with the remaining 53\% being contributed to by 23 states. The role of SMEs in the context of balanced regional development and equitable distribution of income becomes relevant. The sector also contributes to about 7\% of the GDP.

Though there were a variety of enterprises operating in India, no single definition of micro and small enterprises was available until the enactment of the Micro, Small and Medium Enterprises Development Act (MSMED) in 2006.

\section{Definition of SMEs}

SMEs are defined in different ways in different parts of the world. Some define them in terms of assets, while others use employment, shareholder funds or sales as criteria. Some others use a combination of revenue and employment as a hybrid criterion. The MSMED Act of 2006 defines them as:

- enterprises engaged in the production/manufacturing of goods for any industry; and

- enterprises engaged in rendering/providing services.

Enterprises in the manufacturing sector are defined in terms of investment in plant and machinery (excluding land and buildings) and further classified into:

- micro enterprises - investment up to Rs. 2.5 million i.e. up to Rs. 2.5 million (approximately USD $\$ 60,000$ );

- small enterprises - investment between Rs. 2.5 million and Rs. 50 million; and

- medium enterprise - investment between Rs. 50 million and Rs. 100 million.

Service Enterprises: defined in terms of their investment in equipment and further classified into:

- Micro Enterprises - Investment up to Rs. 1 million

- Small Enterprises - Investment above Rs. 1 million \& up to Rs. 20 million

- Medium Enterprises - Investment above Rs. 20 million but below Rs. 50 million. (Development Commissioner MSME, 2009)

The clarity in definitions provided is likely to result in a more focused policy and programme intervention for the various categories of firms. While the SME sector per se has witnessed a phenomenal growth, it is likely that a large number of firms occur in a cluster. Industrial clustering has received attention from various scholars in recent times. Clusters can be defined as sectoral and geographical concentrations of enterprises, in particular small and medium enterprises (SME), faced with common opportunities and threats which can: (i) give rise to external economies (e.g. specialised suppliers of raw materials, components and machinery; and sector specific skills); (ii) favour the emergence of specialised technical, administrative and financial services; (iii) create a conducive ground for the development of inter-firm co-operation and specialisation as well as of co-operation among public and private local institutions to promote local production, innovation and a collective learning approach to SMEs. UNIDO's role and contribution to this effort has been significant (Russo, 1999). Clustering provides 'a collective efficiency' and acts as a catalyst of business growth (Schmitz, 1995).

There are two kinds of clusters in India that are well documented, namely the industrial clusters and the artisan clusters. The total number of clusters in India is estimated to be over 2,400, including about 2,000 rural/artisanal clusters. While industrial clusters dominated the discussions on clusters in the past, in recent years the services clusters have been emerging especially the IT and BPO clusters. These clusters have become the major employment hubs in the country 
(Das et al., 2004). The Government of India has used the cluster development approach to facilitate the growth of industrial clusters in India. The SMEs in a cluster often form part of a global supply chain and their CSR practices have been receiving attention.

\section{CSR and ethics in India}

The evolution and growth of CSR in large corporations in India have been well documented (BCCI, 2007; Mitra, 2007; Sood \& Arora, 2006; Arora \& Puranik, 2004; British Council et al., 2002; Kumar et al., 2001). In recent years, CSR in SMEs in India has been gaining increased attention from practitioners, NGOs and international agencies, but not significantly from scholars. In a comparative study conducted on CSR practices of Dutch Multinationals and SMEs operating in India, it was found that while large multinationals had formulated a CSR policy, which they make public, CSR is not at all institutionalised in SMEs. The reasons attributed to the lack of institutionalisation of CSR include limited resources to do CSR, lack of pressure from the customer or NGOs to do CSR and finally, the inability to see any direct benefit in doing CSR. (CREM, 2004)

Much of the anecdotal evidence in India on SMEs appears to suggest that the ethical orientation of the SMEs is a product of the ethical orientation of its owner. Since the ownership structure of SMEs varies significantly, it is likely that the stringent governance norms that apply to large corporations may not be relevant and enforceable. And this therefore supports the view that the owners/managers in SMEs determine the ethical orientation of the firm. This paper attempts to draw from the existing body of knowledge, from both the academic and popular literature in India to identify the CSR practices and develop a research agenda for responsible business practices in the SME sector in India.

A review of the literature indicates that a few studies have examined the value orientations and ethical stances of Indian managers in large corporations (Monga, 2004; Fisher, Shirole \& Bhupatkar, 2001). One study empirically examines the cultural influences on the judgment of Australian, Malaysian and Indian SME managers to whistle blowing as an internal control mechanism (Chavan \& Lamba, 2007). There is, however, no discussion in the paper about the significance of the choice of SME managers. Since the findings are at the level of cultural influences, the SME managers appear to be just a sample, with no specific behavioural uniqueness attached to them.

In an exploratory study conducted in the Pune Industrial belt in Western India, it was found that compliance to the government laws was seen as being socially responsible. Many SME owners were of the opinion that philanthropy and CSR are one and the same. Since many of the SMEs are at a stage where they are struggling to establish themselves and do not have the manpower or resources to address these issues, they tend to ignore them. (Revenkar, 2004) In a comparative study undertaken on constraints and contingencies of small business in Bangladesh and India, the authors found that many SMEs had similar constraints and contingencies across countries and bribery related variables tended to be fairly similar (Amin \& Banerjee, 2007)

In another study done in an industrial cluster in northern India, the author (Tarun Kumar, 2004) observed that since most SMEs were led by owners, the value system and philosophy of the owner played a significant role in determining the CSR practices undertaken. Many of the SMEs are unable to see any clear benefits by following or practicing CSR. Very few companies had social reports, codes of conduct or stated ethical practices. But the study points that many of the SMEs are involved in some kind of developmental activities. Many of the CEOs of these SMEs were members of Rotary or Lions Clubs and supported various developmental activities initiated by these clubs.

In the last decade, the government is actively promoting cluster development as a strategy to grow SMEs. In 2007, UNIDO along with the Swiss Development Corporation has embarked on a thematic co-operation to identify and disseminate good practices and operational suggestions to improve the participation of the SMEs in the CSR movement. The sports good cluster in the State of Punjab had a multi-stakeholder engagement on CSR in 2008. In a study conducted by the UNIDO (2008) on CSR perceptions and activities in SMEs in five industrial clusters in India, it was found that regardless of the geographical region they hailed from, SMEs tended to behave similarly towards CSR. Many of them considered 'taking care of their employees internally' and 'being involved in community welfare' as their CSR responsibility. The influence of the personal values of the entrepreneurs in determining the choice of CSR activities found support. The position of the SME in the value chain and the financial size seems to positively impact the nature of CSR activities undertaken. When markets and large buyers put pressure on the SMEs, activities like worker education, health and safety compliance are undertaken which in the normal course of business would be unlikely to occur.

In the case of clusters, the role of cluster wide CSR activities assumes significance. The leather cluster is plagued by pollution. The operations in leather tanning - washing, stripping, bleaching, chrome tanning and basification - involve the use of very toxic chemicals and its effluents tend to pollute ground water. Collective CSR efforts will include effluent treatment plants. The adoption of common effluent treatment plants and ecofriendly technologies has not become very widespread 
due to lack of awareness among small firms and also partly due to lack of enforcement of environmental laws amongst small players. (EXIM, 2000)

The influence of codes of conduct and certifications on the ethical practices of SMEs in the export sector requires further investigation. The impact of these codes appears to be the highest in industries like garments, carpets, textiles and beverages that are produced for export. The brand and corporate image of the buyer is impacted in the supply chain and, therefore, most exporters comply with these standards. There are hardly any examples of organisations that adopt these codes of conduct while manufacturing for the domestic market. The reality of codes and standards in India as it exists now covers a very small fraction of the Indian market (Sood \& Arora, 2006).

\section{Implications for future research on CSR}

It is evident from the above discussion, while a few exploratory studies have been conducted on SMEs in India, there is still inadequate understanding of the phenomena. However, it appears that more studies on CSR practices in SMEs have been undertaken compared to the research on ethical orientations of the owners/ managers of SMEs. One of the interesting aspects that have emerged is the definition. In many countries, the definition of SME is based on employment, while in India the definition of SME is based on fixed assets. These definitions are a product of the varying institutional contexts across nations. Does a political economy perspective of looking at 'national business systems' (Matten \& Moon, 2008) provide an alternate lens to understanding SMEs?

There is support in the Indian context also for the influence of personal values of entrepreneurs on CSR practices (Spence \& Rutherford, 2003; Murillo \& Lozano, 2006). It also appears that external pressures from buyers, markets and industry associations shape the values of the entrepreneurs. What is the role of the personal values of the entrepreneur in the manner in which decisions related to ethics and CSR are being taken?

It is interesting to note that very few studies in the Indian context have taken a business ethics perspective. Does the lack of studies in this field indicate unwillingness on the part of the researchers to probe in to the deeper issues of widely prevalent corruption and bribery practices and their impact on SMEs? How SME owners manage and cope in these contexts is an area for further research?

Most of the studies done in the Indian context have largely been qualitative and exploratory in nature. They have been done also by the NGOs or international agencies. Most of the studies have focused on the manufacturing sector. In recent years, the contribution of the services sector to the Indian economy has been increasing. There have been no studies so far examining the impact of CSR practices in SMEs in the services sector. The emergence of the information technology sector in India during the last decade as a significant contributor to the national economy has raised the expectations of a higher corporate responsibility from these organisations. The Indian Diaspora and returnees have played an integral role in the creation of SMEs in this sector. Therefore, there is a need to understand in depth whether this new generation of Western educated SME owners demonstrate different value systems that influence the state of CSR in the sector.

As is evident from the literature review, there is a dearth of research studies on understanding the role of ethics and CSR in SMEs in India. Some of the research areas that emerge are as follows:

- How effective are industry associations in influencing the state of CSR in SMEs? What is the nature and character of this influence?

- Is the CSR intervention at a cluster level likely to be more successful than at the level of the firm? One could explore this question from multiple perspectives - the economic perspective with reduced costs arising out of a cluster orientation, and the cultural context in which peer and community pressure of participation could induce a spill-over effect on CSR practices. Since a number of SMEs in a cluster could significantly impact the field of sustainability and environment, this topic assumes greater significance.

- How do SMEs that engage in CSR manage the additional costs of being responsible? It appears that unlike large corporations, they do not have a market or consumer incentive to be ethical or behave responsibly.

- How do owners engage with the various stakeholders on critical ethical aspects? What are the stances adopted by them? There is an urgent need for research at multiple levels - at the individual, organisation and the industry level.

- What are the variables that impact the adoption of CSR practices by SMEs?

\section{Conclusion}

Since SMEs contribute significantly to the economy and are geographically widely spread in a country like India, their adoption of CSR and ethical practices is crucial to a balanced development. There is a paucity of academic research in this area. In a vast country like India, comprising of 28 states which are economically at different stages of development, a study of the intracountry similarities and differences in adoption of CSR practices in SMEs could be a valuable exercise for policy makers. 


\section{References}

Amin, M.R. \& Bannerjee, S. 2007. Constraints and contingencies of the small business: A comparative perspective. Indian Business and Economics Research Journal, 6(9).

Arora, B. \& Puranik, R. 2004. A review of corporate social responsibility in India. Development, 47(3): 93-100.

Beekman, A. \& Robinson, R. 2004. Supplier partnerships and the small high growth firm: Selecting for success. Journal of Small Business Management, 42: 59-77.

Bombay Chamber of Commerce and Industry. 2007. Socially responsible business: From an SME model to a model SME using the corporate responsibility framework. Mumbai.

British Council, United Nations Development Programme (UNDP), Confederation of Indian Industry (CII), \& PricewaterhouseCoopers. 2002. Corporate social responsibility survey - 2002. British Council, UNDP, CII \& PwC, New Delhi.

Chavan, M. \& Lamba, A.S. 2007. An international perspective on internal controls in small and medium enterprises. The Business Review, 8(1).

CREM Report. 2004. Corporate social responsibility in India: Policy and practices of Dutch Companies. Amsterdam.

Das, K., Nair, T. \& Baskar, V. 2004. Job creation potential of MSEs in clusters and public policy. Report submitted to the ILO, New Delhi (unpublished).

Development Commissioner MSME. 2009. [Online]. Available: http://www.dcmsme.gov.in/ssiindia/msme in.htm. Accessed on 5 December 2009.

Emiliani, M. 2000. Supporting small businesses in their transition to lean production. Supply Chain Management: An international journal, 5: 66-70.

Enderle, G. 2004. Global competition and corporate responsibilities of small- and medium-sized enterprises. Business Ethics: A European review, 13(1): 51-63.

Exim Bank of India. 2000. Institutional support to SMEs: A study of select sectors. Occasional Paper, 76.

Fisher, C.M., Shirole, R. \& Bhupatkar, A.P. 2001. Ethical stances in Indian management culture. Personnel Review, $30(5 / 6)$

Jenkins, H. 2006. Small Business Champions for Corporate Social Responsibility. Journal of Business Ethics, 67: 241-246.

Kumar, R., Murphy, D.F. \& Balsari, V. 2001. Altered images: The 2001 state of corporate responsibility in India poll. Tata Energy Research Institute, New Delhi.

Leutkenhorst. 2004. Corporate social responsibility and the development agenda: The case for actively involving small and medium enterprises. Intereconomics, May/June.

Matten, D. \& Moon, J. 2008. 'Implicit' and 'explicit' CSR: A conceptual framework for a comparative understanding of corporate social responsibility. Academy of Management Review, 33(2): 404-424.

Mitra, M. 2007. It's only Business: India's corporate social responsiveness in a globalised world. New Delhi: Oxford University Press.

Monga, M. 2005. Value orientations: A case study of north Indian manufacturing managers. The Journal of Management Development, 24(7/8).

Moore, G. \& Spence, L. 2006. Editorial: Responsibility and small business. Journal of Business Ethics, 67(3): 219-226.
Murillo, D. \& Lozano, J.F. 2006. SMEs and CSR: An approach to CSR in their own words. Journal of Business Ethics, 67: 227-240.

Pandey, A.P. 2007. Indian SMEs and their uniqueness in the country. MPRA Paper No. 6086. [Online]. Available: http://mpra.ub.uni-muenchen.de/6086/. Accessed on 4 December 2009.

Park, D. \& Krishnan, H.A. 2001. Supplier selection practices among small firms in the United States: Testing three models. Journal of Small Business Management, 39(3): 259-271.

Prasad, V.N. 2008. Labour regulation in small enterprises: Coverage and impact. New Delhi, Institute for Studies in Industrial Development.

Revenkar, A.V. 2004. Corporate social responsibiilty in smalland medium- scale industries. New Delhi, Business Community Foundation Publication.

Richbell, S.M., Watts, H.D. \& Wardle, P. 2006. Owner managers and business planning in small firms. International Small business Journal, 24(5): 496-514.

Russo, F. 1999. Strengthening Indian SME clusters: UNIDO's experience. New Delhi: UNIDO.

Schmitz, H. 1995. Collective efficiency: Growth path for small-scale industry. Journal of Development Studies, 31(4).

Sood, A. \& Arora, B. 2006. The political economy of corporate responsibility in India: Examining the nature of CSR in India. UNRISD, 18.

Spence, L. 1999. Does size matter? The state of the art in small business ethics. Business Ethics: A European review, 8(9): 163-172.

Spence, L. \& Lozano J.F. 2000. Communicating about ethics with small firms: Experiences from the UK and Spain. Journal of Business Ethics, 27(1): 43-53.

Spence, L. \& Rutherford, R. 2003. Small business and empirical perspectives in business ethics. (Editorial) Journal of Business Ethics, 47(1): 1.

Tarun, K. 2004. CSR in industrial areas/SMEs: Activities, policies and strategies in Delhi India. New Delhi, Business Community Foundation.

Third All India Census of Small Scale Industries, 2001-2002. Ministry of SSI, Government of India.

Tilley, F. 2000. Small Firm environmental ethics: How far do they go? Business Ethics: A European Review, 9(1): 31-41.

UNIDO Report. 2008. CSR perceptions and activities of SMEs in seven geographical clusters. New Delhi.

Vyakarnam, S., Bailey, A., Myers, A. \& Burnett, D. 1997. Towards an understanding of ethical behaviour in small firms. Journal of Business Ethics, 16(15): 1625-1636.

Address correspondence to: Vasanthi Srinivasan Indian Institute of Management Bangalore Bannerghatta Road Bangalore 560076 India e-mail:vasanthi@iimb.ernet.in 
Reproduced with permission of the copyright owner. Further reproduction prohibited without permission. 